\title{
Comparative study on three locally developed live orf virus vaccines for sheep in Saudi Arabia
}

\author{
Authors: \\ Fahdel M. Housawi ${ }^{1}$ \\ Eltayb M. Abuelzein \\ Ahmed A. Gamee ${ }^{1}$ \\ Adel I. Alafaleq ${ }^{1}$ \\ Affiliations: \\ ${ }^{1}$ College of Veterinary \\ Medicine and Animal \\ Husbandry, King Faisal \\ University, Saudi Arabia \\ Correspondence to: \\ Eltayb Abuelzein \\ Email: \\ eabuelzein@yahoo.com \\ Postal address: \\ PO Box 80216, Jeddah 21589, \\ Saudi Arabia \\ Dates: \\ Received: 19 Dec. 2011 \\ Accepted: 16 May 2012 \\ Published: 07 Aug. 2012 \\ How to cite this article: \\ Housawi, F.M., Abuelzein, \\ E.M., Gamee, A.A. \& \\ Alafaleq, A.I., 2012, \\ 'Comparative study on three \\ locally developed live orf \\ virus vaccines for sheep in \\ Saudi Arabia', Onderstepoort \\ Journal of Veterinary \\ Research 79(1), Art. \#397, \\ 5 pages. http://dx.doi. \\ org/10.4102/ojvr.v79i1.397
}

C 2012. The Authors.

Licensee: AOSIS

OpenJournals. This work

is licensed under the

Creative Commons

Attribution License.
The epidemiology of orf virus infection in Saudi Arabia (SA) has been researched since 1990. The results obtained during this period indicate that the disease is widespread, has great economic impact and that no vaccine has been used against it. The present study compares the immunogenicity and protective efficacy of three locally developed live orf virus vaccines. Two of them differ in their passage history in Vero cell culture and the third was used as a virulent virus in glycerine buffer. To the best of the authors' knowledge, no similar comparative study has been conducted in the Middle East utilising three types of vaccines prepared from the same virus strain. Selection of the candidate seed orf virus and performance of the quality control tests were as laid out by the OIE for veterinary vaccine production. The vaccine seed virus was a field orf virus isolated from a previous orf outbreak in Saudi Arabia. A simple novel formula was developed to calculate the rate of reduction in the healing time (RHT \%) in the challenged sheep. This allowed direct comparison of the efficacy of the three types of vaccines employed in the present study. The efficacy of each vaccine was tested on a cohort of local Noemi sheep.

\section{Introduction}

Orf is a contagious zoonotic disease of sheep and goats. The causative agent is a Parapoxvirus of the family Poxviridae. The main lesions are usually found on the lips and around the mouth. Sometimes, lesions can spread to the eyes, nostrils and teats (Abuelzein \& Housawi 2009). Under certain circumstances, the disease can take a generalised form throughout the body (Abuelzein \& Housawi 1997). Orf is distributed worldwide and can cause great economic losses to sheep production (Robinson \& Balassu 1981).

Clinically, orf infection has been known to exist in Saudi Arabia for decades, but the first isolation of the virus from a disease outbreak in sheep and goats was made in 1990 (Housawi et al. 1991). From that time, up-to-date, different clinical forms of orf infection, with various severities, have been reported (Abelxein \& Housawi 1997, 2009; Gameel et al. 1995; Housawi et al. 1991). A serological survey revealed that the disease was widespread amongst sheep and goats in the country (Housawi et al. 1992).

In spite of the wide distribution of orf in Saudi Arabia, no vaccine has so far been used for its control. This paper describes a comparative study on three locally developed live vaccines prepared from a local field orf virus with the intention of finding one suitable to be recommended as a candidate vaccine to be used in the Kingdom. Efficacies of the individual vaccines are compared and the results are discussed.

\section{Materials and methods Virus seed stock}

The seed vaccine orf virus (Hou/SA/97) was selected from two field orf viruses which caused fulminant orf outbreaks in sheep and goats in 1995 and 1997. They were obtained from our collection, which was stored at $-86{ }^{\circ} \mathrm{C}$ in glycerol buffered saline at $\mathrm{pH}$ 7.4. Characterisation studies and selection of the seed virus followed the guidelines of the OIE (OIE 2008), which have previously been reported (Housawi 2008).

In the present study, scab material containing the seed virus was made up as a $30 \%$ suspension $(\mathrm{w} / \mathrm{v})$ in phosphate buffered saline (PBS) $\mathrm{pH}$ 7.4. Following centrifugation at $377 \times \mathrm{g}$ for $15 \mathrm{~min}$, the supernatant fluid was collected and antibiotics (procured through the Saudi branch of SigmaAldrich) were added at a concentration of $100 \mathrm{IU} / \mathrm{mL}$ penicillin, $1 \mathrm{mg} / \mathrm{mL}$ streptomycin and $50 \mathrm{IU} / \mathrm{mL}$ mycostatin. The supernatant fluid was used to inoculate monolayers of Vero cell culture, as described by Housawi et al. (1991). When the cytopathic effect (CPE) involved 90\% of the cell monolayer, the cells were harvested and stored in $0.5 \mathrm{~mL}$ aliquots at $-86^{\circ} \mathrm{C}$. 


\section{Study population}

Orf-seronegative indigenous Noemi sheep, aged six months old, were used in the study. They were procured from a farm with no history of orf infection and were kept in complete isolation from other animals to avoid natural orf infection. They were provided with feed and water until used in the experiments.

The ethical approval to use the sheep was provided by the Ethical Committee of the Faculty of Veterinary Medicine and Animal Husbandry, King Faisal University, Saudi Arabia.

\section{Vaccines}

Three types of live orf vaccines were prepared, namely, a live scab vaccine (LSV), Vero cell culture passage 20 vaccine (P20V) and Vero passage 75 vaccine (P75V).

For preparation of the live scab vaccine (LSV), the 'master seed virus' was inoculated into five sheep, as described by Housawi et al. (1993).

The sheep were observed daily until the development of the orf lesions. The scab material was collected and stored at $-86^{\circ} \mathrm{C}$ until used for preparation of the LSV vaccine.

The scab material was made up as a $50 \%(\mathrm{w} / \mathrm{v})$ suspension in PBS pH 7.4, processed as described for the virus seed stock and stored at $-86^{\circ} \mathrm{C}$ until titrated in monolayers of Vero cells (Housawi et al. 1991). The tissue culture infective dose 50 $\left(\mathrm{TCID}_{50}\right)$ was calculated following the method of Read and Muench (1938). The virus suspension was adjusted to contain $10^{6} \mathrm{TCID}_{50} / \mathrm{mL}$ in PBS-glycerol $(50 \% \mathrm{v} / \mathrm{v})$. The formulated vaccine was stored at $4{ }^{\circ} \mathrm{C}$.

To prepare the P20V vaccine, the seed virus was serially passaged in monolayers of the Vero monkey kidney cell culture (Housawi et al. 1993). The 20th passage (P20V) was harvested and titrated in Vero cell monolayers as above. Aluminium hydroxide gel (Sigma-Aldrich, Saudi branch) was then added at a concentration of $1.6 \mathrm{mg} / \mathrm{mL}$ and the final titre was adjusted to $10^{6} \mathrm{TCID}_{50} / \mathrm{mL}$. The vaccine was stored at $4{ }^{\circ} \mathrm{C}$ until used.

The same procedure which was used for preparation of the P20V above was adopted for preparation and formulation of the P75V vaccine, except that the seed virus was serially passaged 75 times in Vero cell culture.

\section{The challenge virus}

Scab material from the experimentally infected sheep as described above, was made into a $50 \%(\mathrm{w} / \mathrm{v})$ suspension in PBS pH 7.4, centrifuged at $377 \times \mathrm{g}$ for $15 \mathrm{~min}$, and the supernatant fluid was collected, processed as before and $0.5 \mathrm{~mL}$ aliquots were stored at $-86^{\circ} \mathrm{C}$ until used in the challenge experiments.

\section{Study design}

The experimental sheep were divided into three groups $(n=30)$ and each group was allocated to one of the respective vaccines. A further fifteen sheep were kept as unvaccinated controls in the challenge experiments.

The group of 30 sheep used in the LSV vaccine experiments was subdivided into two equal groups of 15 sheep, A and B. Both groups were subdivided into three subgroups of five sheep each, A1, A2 and A3, and B1, B2 and B3. The three A-subgroups received only a primary dose of the LSV, whilst the B-subgroups received the primary dose and a booster dose after a month.

The same procedure of creating groups and subgroups was followed for the P20V and P75V vaccines, with the same numbers of sheep for each group. The designations for the P20V groups were D and E, and those for the P75V subgroups were $G$ and F. The subgroups were D1 D2 and D3; E1, E2 and E3; F1, F2 and F3; and G1, G2 and G3. Group D received only the primary P20V vaccine dose and Group E received the P20V vaccine dose and a booster dose a month later. Group $G$ received only the primary P75V vaccine dose and Group F the primary P75V vaccine dose followed by a booster dose a month later. The 15 control sheep were also subdivided into three equal sub-groups and each sub-group was used as a control at a challenging point.

Table 1 shows the vaccination schedule. All sheep of all the subgroups, except the controls, were vaccinated by single scarification $(3 \mathrm{~cm}-4 \mathrm{~cm})$ on the inner thigh of the right hind limb, and $40 \mu \mathrm{L}$ of the vaccine suspension was applied. The vaccinated sheep were observed daily and clinical changes at the sites of vaccination were recorded (Nettleton et al. 1996).

Each of the sheep of all sub-groups, whether they received the primary dose only or the primary dose and a booster or were the controls, were challenged and infected in the manner described above.

To evaluate the degree of protection in each challenged sheep (Nettleton et al. 1996), daily clinical observations were performed on the sites of scarification from the first day following scarification until the scabs had dropped. Accordingly, the mean healing time (MHT) was calculated. Each member of the research team (4 members) took daily readings and the mean was calculated. The criterion for complete healing was judged by presence of a smooth skin surface after the scabs had dropped. Before complete healing,

TABLE 1: Vaccination schedule of the experimental sheep.

\begin{tabular}{lll}
\hline Sheep subgroups & $\begin{array}{l}\text { Primary vaccine } \\
\text { dose }\end{array}$ & Booster dose \\
\hline All subgroups except controls & Yes & - \\
B1, B2, B3, E1, E2, E3, G1, G2, G3 & Yes & $\begin{array}{l}\text { Yes, one month after } \\
\text { primary vaccine }\end{array}$ \\
\hline
\end{tabular}

TABLE 2: Challenging schedule of the vaccinated sheep and the unvaccinated controls.

\begin{tabular}{ll}
\hline Sheep subgroups & $\begin{array}{l}\text { Challenge time (months) after primary } \\
\text { vaccination }\end{array}$ \\
\hline$A 1, B 1, C 1, D 1, E 1, F 1$, G1 & 6 \\
$A 2, B 2, C 2, D 2, E 2, F 2$, G2 & 12 \\
$A 3, B 3, C 3, D 3, E 3, F 3$, G3 & 18 \\
\hline
\end{tabular}


the scab is usually strongly adherent to the lesion and its forcible removal at the inner thigh of the sheep is not easy. Forcible mechanical removal of a scab leads to abrasion and possible bleeding, which can easily be seen. In this study, none of the scabs in the experimental sheep was exposed to forcible mechanical detachment before complete healing and shedding.

The mean reduction time (MRT) per cent, of the orf lesions in the challenged sheep, as compared to the unvaccinated control sheep, was calculated by the following formula:

$\operatorname{MRT} \%=\frac{(\mathrm{C}-\mathrm{V})}{\mathrm{C}} \times 100$

where MRT \% is the mean reduction time \%, C is the mean healing time (days) in the unvaccinated control sheep and $\mathrm{V}$ is the mean healing time (days) in the vaccinated sheep.

\section{The ELISA}

The reference orf antigen used in the ELISA was provided by the Moredun Institute, UK. It was used as 1\% Nonindet P-40 orf specific extract (Nettleton et al 1996). The specific reference sheep anti-orf serum, the non-immune sheep serum collected from orf-free sheep and the mock lamb muscle antigen for ELISA were also provided by the Moredun Institute, UK.

The test sheep sera were collected weekly from each sheep subgroup following the primary vaccination or booster. Sera were also collected weekly from the sheep following each challenge (after 6, 12 and 18 months respectively). The sera were inactivated at $56{ }^{\circ} \mathrm{C}$ for $30 \mathrm{~min}$ and stored at $-20^{\circ} \mathrm{C}$ until used in the ELISA.

An indirect ELISA was employed for the detection of humoral antibodies using the above-mentioned reagents. All volumes of reactants were $50 \mu \mathrm{L}$ per well, incubations at all stages were made at $37^{\circ} \mathrm{C}$, (except for the substrate which was incubated at room temperature $22^{\circ} \mathrm{C}$ ). Washing was by flooding and emptying the wells three times with PBS-Tween (0.01\% Tween 20, Sigma-Aldrich, Saudi branch). The ELISA plates were coated with the reference orf antigen, incubated for two hours and washed. The test sera were diluted as required in PBS-T + 2\% Ovalbumin (Sigma-Aldrich, Saudi branch) and incubated for one hour and the plates were washed. Donkey anti-sheep IgG conjugated to horseradish peroxidase (Sigma-Aldrich, Saudi branch) was added following instructions of the manufacturers, incubated for one hour and washed. The substrate was prepared by adding a $30 \mathrm{mg}$ tablet of orthophenyl diamine (Sigma-Aldrich, Saudi branch) to $75 \mathrm{~mL}$ distilled water followed by $40 \mu \mathrm{L}$ of hydrogen peroxide just before use. The substrate was added and the plates were incubated at room temperature for $10 \mathrm{~min}$ in the dark. The reaction was stopped by adding $1 \mathrm{M}$ sulphuric acid and plates were read in an ELISA Reader (Dynatec Co.) at $450 \mathrm{~nm}$ and the results were interpreted as instructed by the manufacturers.

\section{Statistical analysis}

Following each challenge point (after 6, 12 and 18 months), the ANOVA, in conjunction with a post hoc test, was used to evaluate the difference in protection between all the vaccinated groups and also between the vaccinated groups and the unvaccinated controls.

\section{Ethical considerations}

Ethical approval for use of the experimental sheep and all protocols in this study were obtained from the Ethical Committee of the Faculty of Veterinary Medicine \& Animal Husbandry, King Faisal University, Saudi Arabia.

\section{Results}

Regardless of the vaccine type, typical stages of orf infection, viz., erythema, papule, pustule and scab formation, were seen following primary vaccination or the booster dose in all vaccinated sheep. However, some overlap was observed between the different stages of infection.

Table 3a shows the clinical changes at the site of vaccination following primary vaccination. Table $3 \mathrm{~b}$ shows that, with all three types of vaccines, the duration of healing following the booster dose was shorter than that following the primary dose only.

Tables 4, 5 and 6 show the ANOVA and post hoc statistical analysis results of the different groups receiving the different vaccines and challenged after 6, 12 and 18 months. The results indicate highly significant differences between the groups at the 0.05 level and 95\% confidence interval $(p<0.05)$. Highly significant differences $(p<0.05)$ were also obtained between the vaccinated and unvaccinated control groups of sheep.

Figure 1 illustrates the MRT \% values, following each of the 3 challenges in the vaccinated sheep. Following the six months' challenge of the groups that received one dose of

TABLE 3a: Mean clinical changes at the site of scarification after primary vaccination.

\begin{tabular}{lcccc}
\hline Vaccine type & \multicolumn{4}{c}{ Mean clinical changes in days } \\
\cline { 2 - 5 } & Erythema & $\begin{array}{l}\text { Vesicles and } \\
\text { pustules }\end{array}$ & Scab & Total period \\
\hline L SV & $3.2 \pm 1.3$ & $6.6 \pm 0.9$ & $12.5 \pm 2.5$ & 22.3 \\
P 20V & $3.2 \pm 1.3$ & $6.5 \pm 0.9$ & $12.4 \pm 2.6$ & 22.1 \\
P 75V & $3.2 \pm 1.3$ & $7.4 \pm 2.1$ & $12.2 \pm 2.7$ & 22.8 \\
\hline
\end{tabular}

TABLE 3b: Mean clinical changes at the site of scarification after the booster dose.

\begin{tabular}{lcccc}
\hline Vaccine type & \multicolumn{4}{c}{ Mean clinical changes in days } \\
\cline { 2 - 5 } & Erythema & $\begin{array}{c}\text { Vesicles and } \\
\text { pustules }\end{array}$ & Scab & Total period \\
\hline L SV & $2.6 \pm 0.8$ & $4.8 \pm 0.5$ & $9.2 \pm 1.8$ & 16.6 \\
P 20V & $2.6 \pm 0.8$ & $4.2 \pm 0.5$ & $8.2 \pm 1.8$ & 15 \\
P 75V & $2.6 \pm 0.8$ & $4.6 \pm 0.6$ & $9.2 \pm 1.8$ & 16.4 \\
\hline
\end{tabular}

TABLE 4: ANOVA results for all the vaccinated and unvaccinated sheep groups following the 6 month challenge.

\begin{tabular}{lllll}
\hline Vaccine & $\begin{array}{l}\text { Mean healing } \\
\text { time }\end{array}$ & s.d. & $\boldsymbol{F}$ & $\boldsymbol{p}$ \\
\hline P20V & 18.500 & 2.068 & 53.667 & 0.000 \\
LSV & 22.700 & 3.093 & 53.667 & 0.000 \\
P75V & 21.200 & 1.229 & 53.667 & 0.000 \\
Controls & 30.000 & 1.632 & 53.667 & 0.000 \\
\hline
\end{tabular}

s.d., standard deviation. 
TABLE 5: ANOVA results for all the vaccinated and unvaccinated sheep groups following the 12 month challenge.

\begin{tabular}{lllll}
\hline Vaccine & Mean healing time & s.d. & $\boldsymbol{F}$ & $\boldsymbol{p}$ \\
\hline P20V & 20.000 & 1.63 & 77.948 & 0.000 \\
LSV & 22.000 & 1.054 & 77.948 & 0.000 \\
P75V & 23.000 & 2.173 & 77.948 & 0.000 \\
Controls & 30.000 & 1.054 & 77.948 & 0.000 \\
\hline
\end{tabular}

s.d., standard deviation $F$, frequency; $p$, probability value.

TABLE 6: ANOVA results for all the vaccinated and unvaccinated sheep groups following the 18 month challenge.

\begin{tabular}{lllll}
\hline Vaccine & Mean healing time & s.d. & $\boldsymbol{F}$ & $\boldsymbol{p}$ \\
\hline P20V & 20.000 & 1.699 & 108.750 & 0.000 \\
LSV & 25.000 & 1.054 & 108.750 & 0.000 \\
P75V & 26.000 & 0.942 & 108.750 & 0.000 \\
Controls & 30.000 & 1.154 & 108.750 & 0.000 \\
\hline
\end{tabular}

s.d., standard deviation $F$, frequency; $p$, probability value.

the relevant vaccine, the MRT \% value was highest for the P20V (33.3\%), followed by that for the P75V (30\%) and the LSV group (16.7\%) respectively. Following the 12 months' challenge, the highest MRT \% value was scored for the sheep that received the P20V (30\%), followed by those that received the LSV (26.7\%) and the lowest was scored by the P75V (16.7\%) group. Following the 18 months' challenge, the MRT $\%$ values were $33.3 \%, 16.7 \%$ and $13.3 \%$ for the P20V, LSV and P75V respectively.

Figure 2 illustrates the MRT \% values for the boostered sheep at each challenge point. At the 6 months' challenge, the MRT $\%$ values were $43.3 \%, 33.3 \%$ and $30 \%$ for the P2OV, LSV and the P75V respectively. At the challenge point after 12 months, the MRT \% values were $36.7 \%$ for the P20V and $26.7 \%$ for both the LSV and P75V. Following the challenge point at 18 months, the MRT \% values were 33.3\%, $16.7 \%$ and $13.3 \%$ for the P20V, LSV and P75V respectively.

Figure 3 represents a typical pattern of ELISA values reflecting the serum antibody levels following challenges (as exemplified by the P20V vaccinated sheep following the 6 months' challenge). The optical density (OD) values shown on the $y$-axis represent net values obtained by subtracting the background reactivity of the pre-immune serum. All samples were measured in duplicate. As seen in Figure 3, the mean OD value at the day of challenge (day zero) was high (2.93 \pm 0.12 ) then dropped to $2.02 \pm 0.15$ on day 7 post challenge (PC), (most probably due to neutralisation by the challenge virus). On day $14 \mathrm{PC}$, the OD level rose to $2.83 \pm 0.13$, then there was a slight drop by day 21 PC $(2.52 \pm 0.15)$ and it remained almost at that level until day 28 PC $(2.51 \pm 0.14)$.

The challenged unvaccinated control sheep were ELISA seronegative at the time of challenge but seroconverted after challenge. The OD values started rising from day 7 PC to reach a high level by day 28 PC.

\section{Discussion}

Unlike other animal viral vaccines, which may confer full protection to the vaccinated animal, orf vaccines do not give $100 \%$ protection. Therefore, the main purpose behind orf

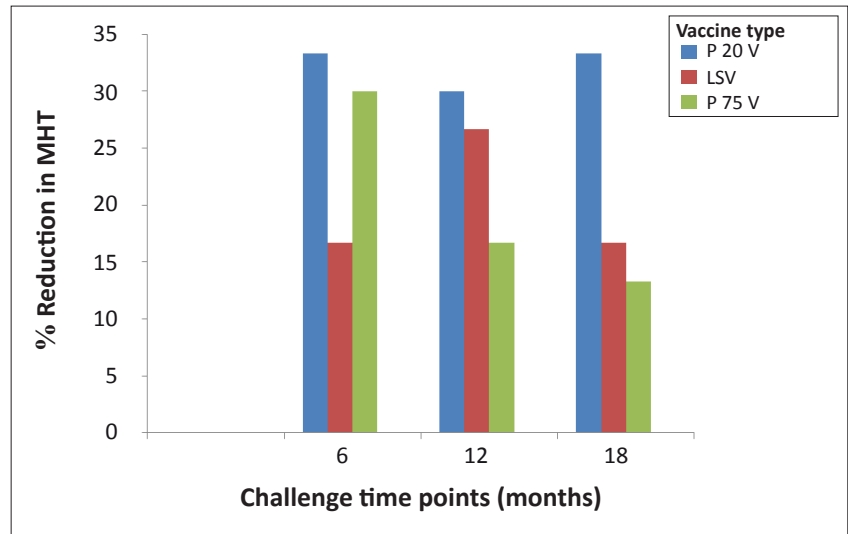

MHT, mean healing time.

FIGURE 1: Percentage reduction in the mean healing time following challenge of the sheep that received a single vaccine dose only.

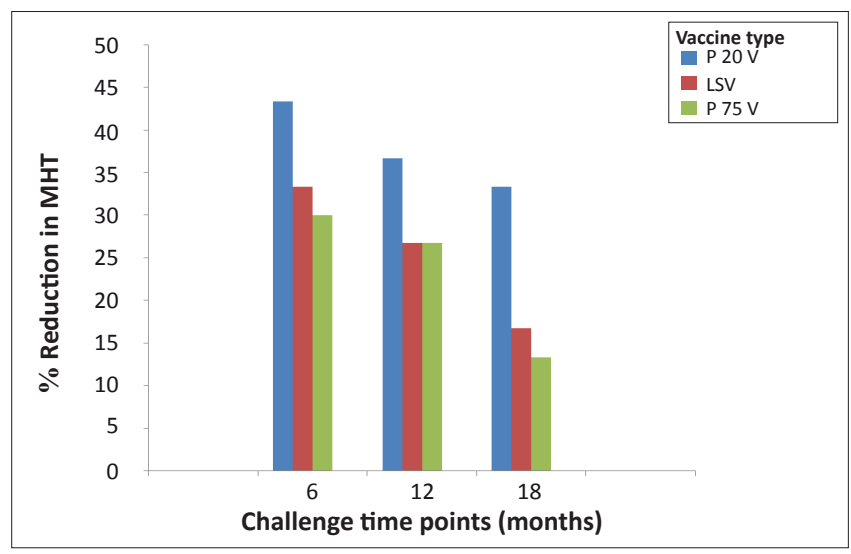

MHT, mean healing time.

FIGURE 2: Percentage reduction in the mean healing time following challenge of the sheep that received the booster vaccine dose.

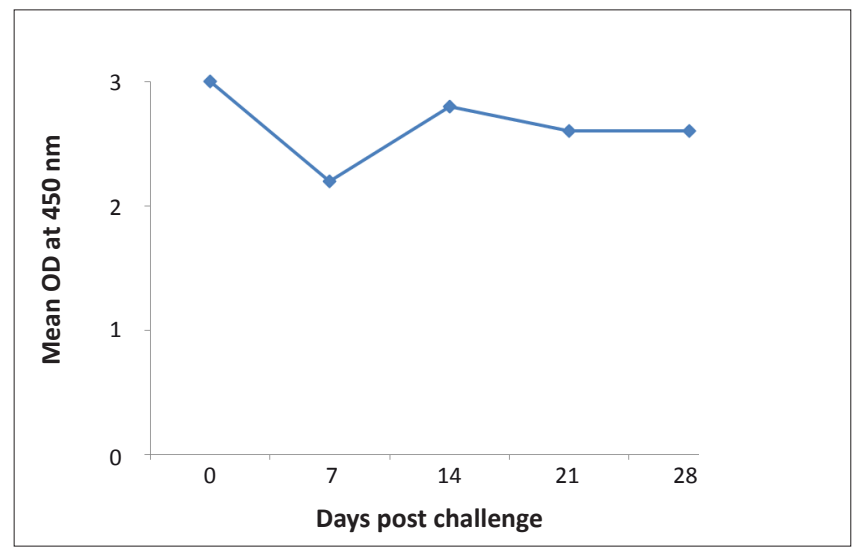

OD, optical density.

FIGURE 3: Typical pattern of ELISA mean values in sheep sera following the 6 months challenge. Sera were diluted at $1 / 50$ dilution. The optical density (OD) values shown on the $y$-axis are net-values obtained by subtracting the background reactivity of the control non-immune serum.

vaccination is to protect vaccinated animals from the severe effects of the field virus and to offer appreciable reduction in the duration of the clinical disease.

The present study was undertaken to develop a local efficacious vaccine to be used in Saudi Arabia, where orf infection is widespread. Accordingly, three types of live 
vaccines were developed from a local field orf virus so as to choose the most efficacious to be recommended for use in the field. To the best of the authors' knowledge, no similar comparative study, utilising three types of vaccine prepared from the same virus strain, has been conducted in the Middle East nor in the developing world.

Each of the developed vaccines gave clinical responses at the site of vaccination (indicating viability), induced production of humoral antibodies and conferred some degree of protection.

To evaluate the ability of the vaccine to minimise the time of healing following challenge, a simple formula was developed in this study to calculate the rate of mean reduction in the healing time (MRT \%) following challenge. This exercise enabled direct comparison of the efficacy of the three types of vaccines.

Comparing the efficacy of the three types of vaccines, it could be seen that P20V gave the best results. It induced highly significant reduction in disease duration following the three challenge points. It is clear that the twenty passages of the orf virus in Vero cell culture were satisfactory for the production of a safe and efficacious P20V orf vaccine under our local conditions. It is rather difficult to explain why this occurs, but it is likely that at this passage level the virus has lost its high virulence but can maintain its immunogenicity to confer good protection.

Generally speaking, the results for the three types of vaccine indicate that protection in the boosted sheep was better than in those that received only one dose of the vaccine, although no improvement was seen in the P75V results.

Published data indicate that orf protection is predominantly cell mediated. However, humoral antibodies are also vital in the activation of the killer cell (antibody dependent cytotoxic cell - ADCC), which is an important branch of the cellmediated immunity. The present study has illustrated that the three types of vaccine induced the production of humoral antibodies following primary vaccination of the sheep and resulted in an amnesic response following the booster dose.

\section{Conclusion}

This study involved the development of three different orf vaccines from the same virus isolate, for the first time in the Middle East and probably elsewhere. Two of the vaccines were prepared by passaging at different levels in Vero cell culture; and the third was used as a virulent virus in glycerine buffer saline. The P20V was found to be the most efficacious of the three vaccines, and is recommended for use in the field in Saudi Arabia. In the present study, a novel formula was also developed to calculate the healing time as a percentage of that seen in control animals instead of scoring it in days. This will enable researchers in the field of orf vaccinology to compare their results directly.

\section{Acknowledgements}

The authors would like to thank King Abdulaziz City for Science and Technology for Grant Number AT-19-6 and for their ever continuous encouragement. We also would like to thank Dr P. Nettleton for provision of the reference ELISA antigen and antiserum. The technical assistance of Mr A. Khars and the kind help of Dr Nahla Khames in the statistical analysis are appreciated.

\section{Competing interests}

The authors declare that they have no financial or personal relationship(s) which may have inappropriately influenced them in writing this paper.

\section{Authors' contributions}

F.M.H. (King Faisal University) was the principal investigator. All authors participated in the project design and brain storming discussions. E.M.A. (King Faisal University) prepared the vaccines. E.M.A. (King Faisal University) and F.M.H. (King Faisal University) performed the ELISA experiments. A.A.G. (King Faisal University) was the pathologist of the team. He inoculated the sheep with the different vaccines. A.A.G. (King Faisal University), E.M.A. (King Faisal University), F.M.H. (King Faisal University) and A.I.A. (King Faisal University) participated in reading of the vaccination \& challenge results and subsequent followup. E.M.A. (King Faisal University), F.M.H. (King Faisal University), A.A.G. (King Faisal University) and A.I.A. (King Faisal University) wrote the manuscript. E.M.A. (King Faisal University) is the corresponding author.

\section{References}

Abuelzein, E. \& Housawi, F., 1997, 'Severe long-lasting contagious ecthyma infection in a goat's kid', Journal of Veterinary Medicine Series B 44, 561-564. http://dx.doi. org/10.1111/j.1439-0450.1997.tb01008.x

Abuelzein, E. \& Housawi, F., 2009, 'Drastic cutaneous multi-focal orf infection in goats, causing severe dysfunctioning', Revue Scientifique et Technique (OIE) 28, 10251029. PMid:20462159

Andrewes, C. \& Horstman, D., 1949, 'The susceptibility of viruses to ethy1 ether', Journal of General Microbiology 3, 290-292. PMid:18149942

Gameel, A., Abuelzein, E., Housawi, F., Agib, A. \& Ibrahim, A., 1995, 'Clinicopathological observations on naturally occurring contagious ecthyma in lambs in Saudi Arabia', Revue d'Elevage et de Médecine Vétérinaire des Pays Tropicaux 48, 233-235. PMid:8745744

Housawi, F., 2008, 'Characterization of candidate seed orf viruses to be used as vaccine in sheep and goats in Saudi Arabia', Scientific Journal King Faisal University (Basic Sciences) 9, 137-146.

Housawi, F. \& Abuelzein, E., 1991, 'Orf infection following ear tagging in goats', Revue d'Elevage et de Médecine Vétérinaire des Pays Tropicaux 44, 277-278.

Housawi, F., Abuelzein, E., Amin, M. \& Al Afaleq, A., 1991, 'Orf infection in sheep and goats in Saudi Arabia', Veterinary Record 128, 550-551. http://dx.doi org/10.1136/vr.128.23.550, ṔMid:1909477

Housawi, F., Abuelzein, E., Al Afaleq, A. \& Amin, M., 1992, 'Serosurveillance for orf antibodies in sheep and goats in Saudi Arabia employing the ELISA technique',
Journal of Comparative Pathology 106, 153-158. http://dx.doi.org/10.1016/00219975(92)90044-U

Housawi, F., Abuelzein, E., Gameel, A. \& Al Afaleq, A., 1993, 'A close comparative study on the response of sheep and goats to experimental orf infection' Journal of Veterinary Medicine Series B 40, 272-282. http://dx.doi. org/10.1111/j.1439-0450.1993.tb00138.x

Marklew, S., 1995, 'Assessment of cell-culture grown on virus vaccines in sheep', in M. Schwyzer (ed.), Immunology Viral Infections: Proceedings of the 3rd Congress European Society, Veterinary Virology, September 4-7, 1995, pp. 305-309.

Nettleton, P., Brebner, J., Pow, T., Gilray, J., Bell, G. \& Reid, H., 1996, 'Tissue culture propagated orf virus vaccine protects lambs from orf virus challenge', Veterinary Record 138, 184-186. http://dx.doi.org/10.1136/vr.138.8.184, PMid:8677620

Office International Epizooties (OIE), 2008, 'Bovine Viral Diarrhoea', Manual of Standards for Diagnostic Tests and Vaccines, Chapter X.5, p. 18, from http://www. oie.int

Reed, L. \& Muench, G., 1938, 'A simple method of estimating fifty percent point', American Journal of Hygiene 27, 493.

Robinson, A. \& Balassu, T., 1981, 'Contagious pustular dermatitis (orf)', Veterinary Bulletin 51, 771-782.

Talhouk, R. \& Elzein, E., 1986, 'Characterization of a cell culture adapted goat pox virus', Journal of Veterinary Medicine Series B 33, 543-551. http://dx.doi. org/10.1111/j.1439-0450.1986.tb00066.x 